\title{
Геологическое строение Алакурттинской структуры, как части Тикшеозерского зеленокаменного пояса
}

Матреничев А.B., Матреничев B.A.

АО «Северо-Западное ПГО», Санкт-Петербург, matrenichev@gmail.com

Аннотация. В результате исследований установлено, что Алакурттинская структура является частью Тикшеозерского зеленокаменного пояса и характеризуется двучленным строением разреза. В основании разреза залегают метаосадочные образования, в верхней - метавулканиты. Источником сноса для метаосадков служили гранито-гнейсы фундамента с возрастом зональных цирконов $2820 \pm 10$ млн. лет для ядер и $2763 \pm 6$ млн. лет для оторочек (U-Pb, Zr, SHRIMPII). Осадочные образования интрудированы габбро-амфиболитами с возрастом $2700 \pm 7$ млн. лет (U-Pb, Zr, SHRIMPII).

Ключевые слова:Тикшеозерский зеленокаменный пояс, архей, метаосадки, Фенноскандинавский щит.

\section{Geology of the Alakurtty structure - a part of the Tiksheozero Greenstone Belt}

\author{
Matrenichev A.V., Matrenichev V.A. \\ «Severo-Zapadnoe PGO»PLC, matrenichev@gmail.com
}

\begin{abstract}
In this study, we report geology of the newly defined Alakurtty structure as a part of the Tiksheozero Greenstone Belt. The Alakurtty structure has two main units - metasedimentary beds and mafic beds. Granite-gneisses of the Archean basement were the main source for metasediments. The cores of zircons from sediments give $2820 \pm 10$ $\mathrm{Ma}$ and rims give $2763 \pm 6 \mathrm{Ma}$ (U-Pb, SHRIMP II). The metasediments are intruded by gabbro-amphibolites with zircons $2700 \pm 7 \mathrm{Ma}$ (U-Pb, SHRIMP II).
\end{abstract}

Key words:Tiksheozero greenstone belt, Archean, metasediments, Fennoscandian Shield.

\section{Введение}

Нерасчлененные архейские образования каликорвинского метаморфического комплекса узкой полосой протягиваются в субмеридианальном направлении в Северо-Карельской структурноформационной зоне вдоль границы Карельской гранит-зеленокаменной области с Беломорским подвижным поясом. С одной стороны, по своей структурной позиции каликорвинский метаморфический комплекс связан с образованиями Тикшеозерского зеленокаменного пояса (ТЗП), однако непосредственных взаимоотношений между ними не установлено, с другой, его взаимоотношения с беломорским метаморфическим комплексом неясны.

Биотитовые, двуполевошпат-биотитовые гнейсы и подчиненные им амфиболиты Алакурттинской структуры, залегающие на породах фундамента, были описаны Е.В. Нефедовым при поисковосъемочных работах (Нефедов, 1959ф). В дальнейшем, А.Д. Даином была закартирована куполовидная структура, которая обрамляет Алакурттинский купол, сложенный позднелопийскими диоритоидами (Даин, 1974ф). Биотитовые, двуполевошпат-биотитовые гнейсы и амфиболиты Е.В. Нефедовым и А.Д. Даином рассматривались в качестве образований керетьской и хетоламбинской толщ беломорской серии.

Впервые предположение о том, что Алакурттинская структура каликорвинского метаморфического комплекса является зеленокаменной постройкой было сделано А.М. Ремизовой на основе анализа работ предшественников, которая объединила двуполевошпат-биотитовые гнейсы и амфиболиты в алакурттинскую толщу (Ремизова, 2007).

В данной работе на основании полевых работ, петрографических, геохимических и изотопных исследований обоснована правомерность данного предположения, приводятся новые данные о геологическом строении, составе и происхождении пород алакурттинской толщи.

\section{Геологическое строение}

Супракрустальные образования Алакурттинской структуры залегают на породах фундамента - огнейсованных плагиогранитах и тоналитовых гнейсах кестеньгского комплекса (рис. 1). 


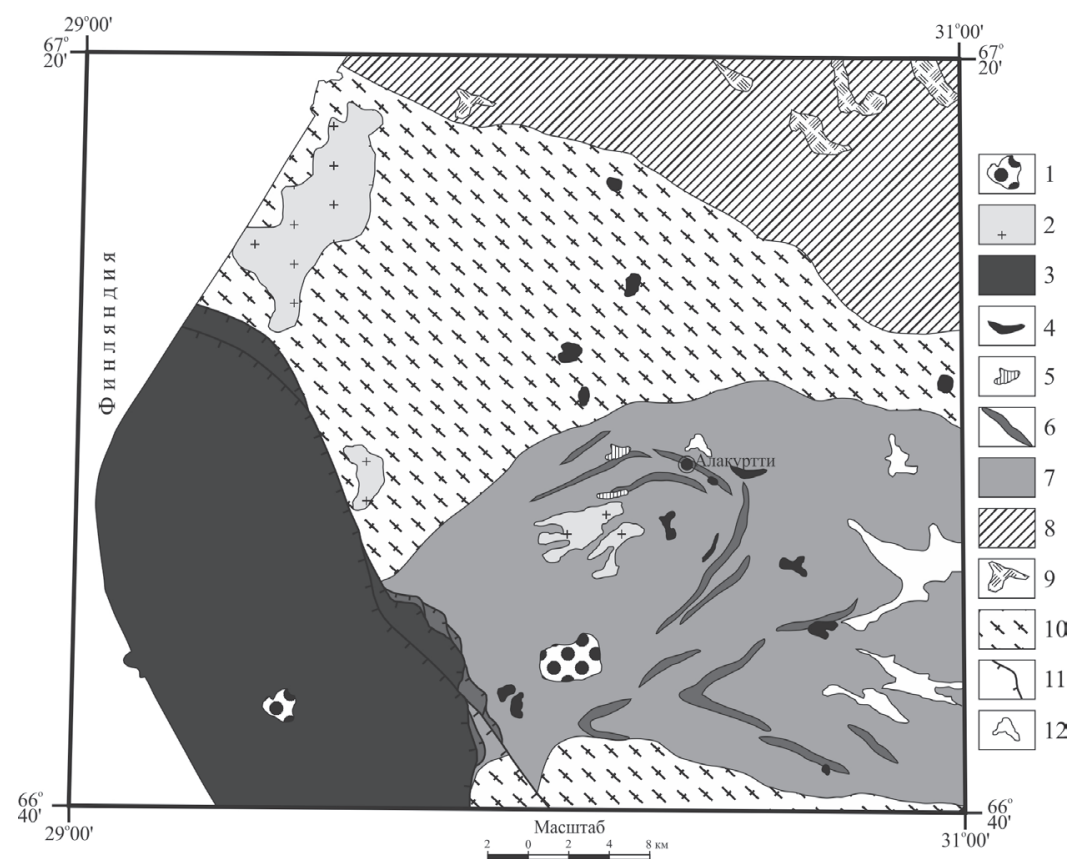

Рис. 1. Схема геологического строения Алакурттинской структуры. 1 - щелочные интрузии; 2 - граниты, 3 - Куолаярвинская структура; 4, 5 - габбро-амфиболиты; 6, 7-алакурттинская толща: 6 - амфиболиты, 7 - метаосадки; 8, 9 - Беломорский подвижный пояс; 10 - гранитогнейсы фундамента; 11 - основные надвиги; 12 - озера.

Fig. 1. The map of the Alakurtty structure.

1 - alcaline intrusions; 2 - granites; 3 - Kuolayarvi structure; 4, 5 - gabbroamphibolites, 6, 7 - Alakurtty unit: 6 - mafic rocks, 7 - metasediments; 8, 9 - White Sea belt; 10 - basement; 11 - main thrusts; 12 - lakes.
Разрез алакурттинской толщи характеризуется двучленным строением. В основании разреза образования нижней подтолщи сложены метаморфизованными осадочными породами. В настоящее время они представляют собой грубополосчатые двуполевошпатовые биотит - амфиболовые гнейсы. Как правило, полосчатая текстура обусловлена чередованием существенно полевошпатовых прослоев и прослоев кварц - биотитовых или кварц - биотит - амфиболовых, причём содержание темноцветных минералов может варьировать в широких пределах (рис. 2). Эта часть разреза насыщена многочисленными мелкими телами базитов и гипербазитов, а также - мелкими телами синколлизионных гранитов.

Наилучшая сохранность первичных признаков осадочных пород характерна для лейкократовых пород с минимальным количеством темноцветных минералов. С увеличением количества биотита и амфибола в породе интенсивность метаморфической перекристаллизации резко возрастает, что связано с повышением количества водосодержащих минералов в породах. В результате структуры и минералогические признаки осадочного генезиса полностью редуцируются.

Среди хорошо сохранившихся реликтов структур осадочных пород преобладают структуры проксимальной части турбидитной системы, для которой характерно широкое развитие средне и грубозернистых плохо сортированных песков. Как правило их текстуры однородные, массивные, редко линзовидные или слабовыраженные градационные. Микроскопически такие структуры определяются по очень низкой гранулометрической зрелости метаосадков и бимодальному распределе-
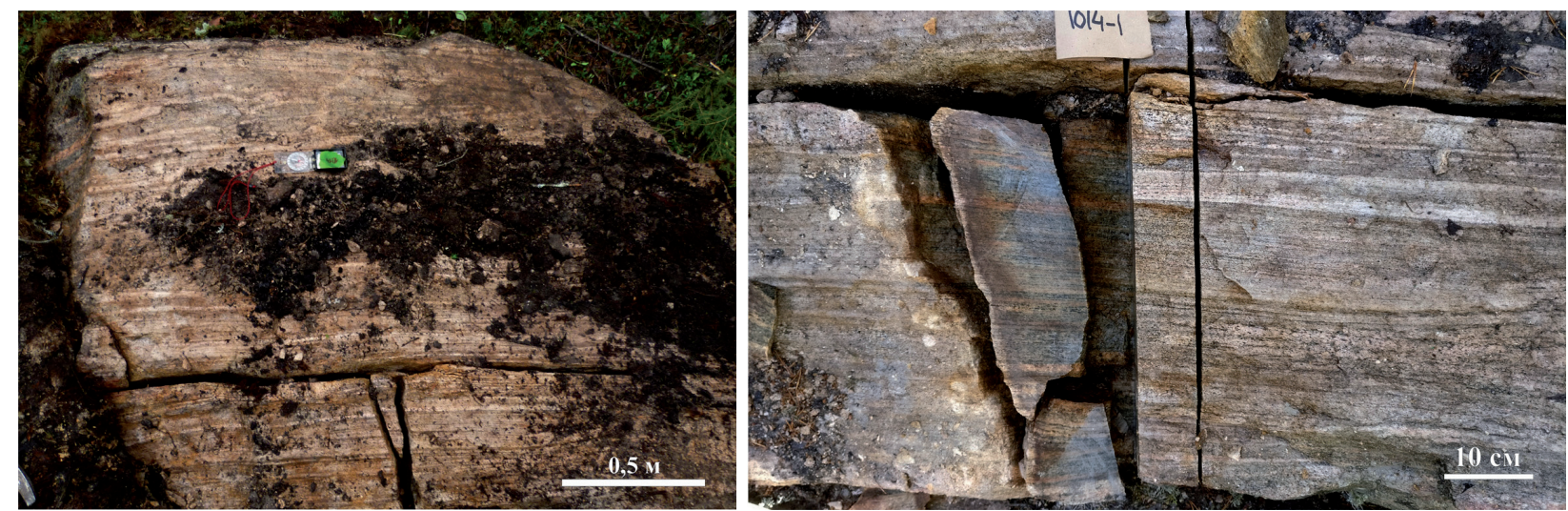

Рис. 2. Парагнейсы нижней подтолщи алакурттинской толщи с полосчатой текстурой.

Fig. 2. Layer structure in metasedimentary gneisses of the Alakurtty unit. 

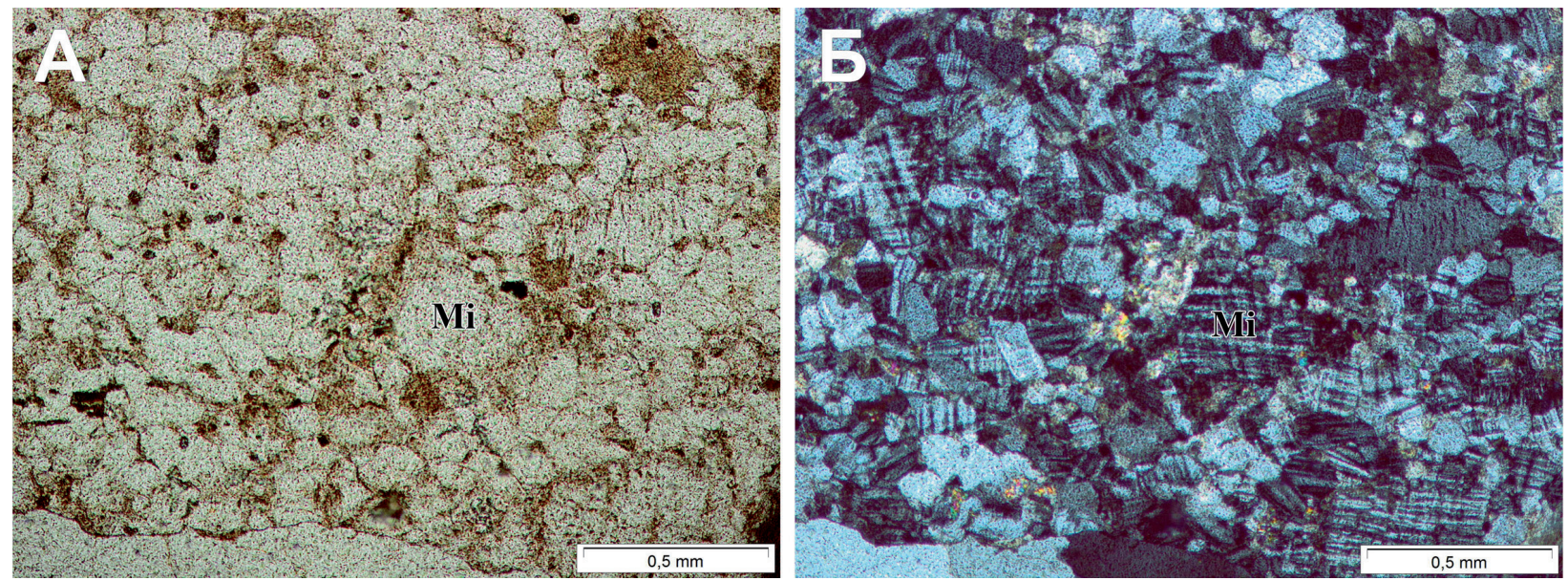

Рис. 3. Микрофотография шлифа № 4527-2.

Плохосортированные метапесчанники алакурттинской толщи. А - без анализатора, Б - николи скрещены.

Fig. 3. Poorly sorted metasandstones of the Alakurtty unit.

нию гранулометрического состава в них. Наиболее четко структуры плохо сортированных песчаников можно наблюдать в шлифе № 4527-2. Здесь хорошо выделяется бимодальность гранулометрического состава, которая формируется одними и теми же минералами. Крупные грубоокатанные зёрна микроклина по размеру варьируют от 3 мм до 8-10 мм. Более окатанные зерна плагиоклаза в целом несколько меньше по размеру: 2-4 мм. Выделения кварца полностью гранулированы и, как правило, имеют сильно уплощённую форму, но при этом площадь зерен сопоставима с площадью крупных выделений микроклина.

Крупноразмерные зёрна микроклина, плагиоклаза и кварца погружены в мелкозернистую матрицу, сложенную теми же минералами с размером зёрен менее 1 мм (0.8-0.2 мм). В мелкозернистом матриксе заметно преобладает микроклин, значительно меньше в матриксе кварца, а плагиоклаз практически отсутствует (рис. 3).

Структурные особенности в породах дистальных фаций турбидитной системы при метаморфизме сохраняются значительно хуже. Плохая сохранность первичных осадочных структур в этих породах обусловлена повышенной концентрацией водосодержащих минералов в них и как следствие, более высокой интенсивностью метаморфической перекристаллизации, которая полностью стирает ранние структуры.
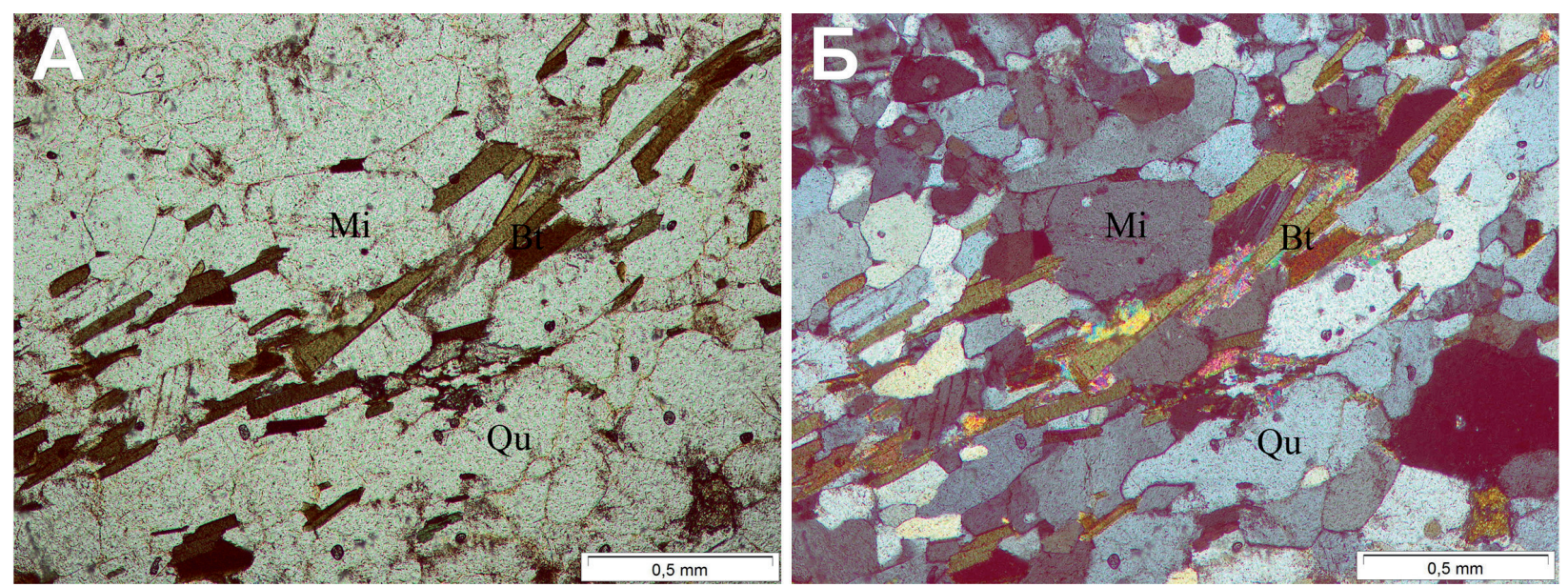

Рис. 4. Микрофотография шлифа № 4521-1.

Реликты градационной и минеральной микроритмичности в метаосадках алакурттинской толщи. А - без анализатора, Б-николи скрещены.

Fig. 4. Relicts of granular and mineralogical rhythms in metasediments of the Alakurtty unit. 
В редких случаях, (шлиф № 4521-1), сохраняются реликты микроритмичности, которая подчеркивается различием минерального состава градационной слоистости (рис. 4). Здесь выделяются полосы различного минерального состава, где чередуются прослои сложенные однородным среднезернистым агрегатом кварца и биотита с прослоями, сложенными плохо сортированными микроклиновыми песчаниками с бимодальным распределением гранулометрического состава. Такие песчаники характерны для пород проксимальной фации. В результате метаморфической инверсии зернистость первичных алевритовых прослоев значительно увеличилась, что и привело к формированию однородных среднезернистых кварц-биотитовых прослоев. Одновременно с этим, структурно-минералогические преобразования для песчанистых существенно микроклиновых прослоев были минимальны. В песчанистых прослоях сохраняются сильно уплощённые крупные зёрна микроклина, погружённые в относительно мелкозернистый плохо сортированный матрикс микроклинового же состава.

Среди парагнейсов алакурттинской толщи выделяются амфиболиты, гранатовые амфиболиты и амфиболовые сланцы верхней подтолщи, гранитизированные в разной степени. Процессы гранитизации амфиболитов проявлены в развитии по сланцеватости лейкосом плагио- и плагиомикроклиновых мигматитов. Первичные структурно-текстурные особенности в амфиболитах не сохраняются, в связи с этим, вопрос о генезисе этих образований остаётся дискуссионным.

Амфиболиты - темно-серого цвета до черных с зеленоватой побежалостью, мелкосреднезернистые, порфиробластические, с однообразным минеральным составом: обыкновенная роговая обманка, олигоклаз-андезин, кварц, биотит, часто к основной ассоциации добавляются гранат и цоизит. Амфиболиты обладают преимущественно тонкосланцеватыми, реже массивными текстурами. Породы характеризуются мелко-крупнозернистыми, гранонематобластовыми структурами, параллельно-сланцеватыми текстурами.

По химическому составу амфиболиты и гранатовые амфиболиты соответствуют толеитовым базальтам и реже андезибазальтам с содержаниями (масс. \%) $\mathrm{SiO}_{2}=45-57 \%$; $\mathrm{Na}_{2} \mathrm{O}+\mathrm{K}_{2} \mathrm{O}=1.5-5 \%$; $\mathrm{MgO}=5-10 \% ; \mathrm{Fe}_{2} \mathrm{O}_{3}=10-15 \% ; \mathrm{TiO}_{2}=0.5-1.5 \% ; \mathrm{Al}_{2} \mathrm{O}_{3}=13-16.5 \% ; \mathrm{CaO}=5-12 \%$; индекс $\mathrm{Mg \#} \mathrm{при}$ этом 0.5-0.7.

\section{Возраст Алакурттинскойструктуры}

Для того, чтобы оценить возраст образования алакурттинской толщи были выделены цирконы из метаосадков и прорывающих их интрузий основного состава. Цирконы из метаосадков характеризуются магматическим обликом - удлиненные зерна с хорошо выраженной огранкой, темно серой каймой (в BSE) и осцилляторной зональностью в центральной части. Фигуративные точки полученных возрастов для метаосадков на диаграмме с конкордией ${ }^{206} \mathrm{~Pb} /{ }^{238} \mathrm{U}-{ }^{207} \mathrm{~Pb} / 235 \mathrm{U}$ формируют несколько кластеров с возрастами от 2800 до 2750 млн. лет. Через четыре фигуративные точки для темно серых кайм возможно провести дискордию, с верхним пересечением конкордии в $2763 \pm 6$ млн. лет $(\mathrm{CКВО} \mathrm{=0.28).} \mathrm{Дискордия,} \mathrm{проведенная} \mathrm{через} \mathrm{три} \mathrm{фигуративные} \mathrm{точки} \mathrm{для} \mathrm{ядер}$ цирконов характеризуется верхним пересечением с конкордией в значении $2820 \pm 10$ млн. лет $(\mathrm{CKBO}=0.27)$.

Полученные значения возрастов для цирконов характеризуют возраст образования размывающихся гранитоидов фундамента. Следовательно, метаосадки алакурттинской толщи моложе этих значений.

$\mathrm{U}-\mathrm{Pb}$ изотопный возраст цирконов магматического габитуса из метаморфизованных габброидов, прорывающих метаосадки характеризуется значением $2700 \pm 7$ млн. лет.Таким образом, интервал времени формирования супракрустальных образований алакурттинской толщи можно оценить 2763-2700 млн. лет.

\section{Обсуждение результатов и выводы}

В непосредственной близости от изученной Алакурттинской структуры находятся Каликорвинская и Кичанская структуры, интерпретируемые Р.И. Милькевич как фрагменты ТЗП. В основании разреза Каликорвинской структуры залегают высокомагнезиальные толеитовые метавулканиты 
с прослоями метаграувакк, которые перекрываются кислыми метавулканитами, по составу соответствующие андезитам и дацитам, U-Pb возраст дацитов по циркону составляет 2785-2766 млн. лет. Такие разрезы характерны для зрелых зеленокаменных поясов Карелии (Милькевич и др., 2007).

Подобные ассоциации пород в пределах ТЗП описаны и в Кичанской структуре (Милькевич и др., 2003, 2007; Калинин и др., 2017). Здесь были выделены три свиты. В основании разреза - верхнеозерская свита, сложенная толеитовыми и коматиитовыми метабазальтами с прослоями метаграувакк. Возраст детритовых цирконов из метаграувакк составляет $2766 \pm 21$ млн. лет. Выше - Хизоварская свита, сформированная метатуфами и метатуффитами с возрастом $2735 \pm 20$ млн. лет. Верхняя часть разреза представлена отложениями челозерской свиты - метаандезибазальтамиметаандезитами и метадацитами, с возрастом $2720 \pm 4$ млн. лет (Левченков и др., 2003).

Возраст образования супракрустальных образований Алакурттинской структуры соответствует времени формирования пород ТЗП в Каликорвинской и Кичанской структурах. При этом, определения возрастов кислых вулканитов Каликорвинской и Кичанской структур характеризуют верхнюю часть разреза ТЗП, а датировки для алакурттинской толщи - нижнюю. Большая часть разреза алакурттинской толщи сложена метаосадочными образованиями нижней подтолщи, амфиболиты (метабазальты?) верхней подтолщи занимают не более 10-20 \% объема разреза, а метавулканиты кислого и коматиитового состава отсутствуют.

Строение разрезов, наблюдаемое для Алакурттинской структуры - с большим количеством осадочных образований и небольшим количеством вулканитов характерно для начальных стадий формирования рифтовых систем. Следовательно, можно предполагать, что развитие рифтовой системы ТЗП происходило в направлении с юга на север. Во время формирования коматиитовых и высокомагнезиальных толеитовых вулканитов в Кичанской и Каликорвинской структурах, Алакурттинская структура представляла собой прогиб, в котором происходило интенсивное осадконакопление.

\section{Литература}

1. Даин А.Д., Иванов А.Н. и др. О результатах комплексных геолого-поисковых работ на медно-никелевые руды, проведенных Алакурттинской партией в Кандалакшском районе Мурманской области в 1971-1974 гг. ФГУ ТФИ по Мурм. обл. 1974.

2. Калинин А.А., Астафьев Б.Ю., Воинова О.А., БаяноваТ.Б., Хиллер В.В. Геологическое строение и перспективы рудоносности Кичанской структуры Тикшеозерского зеленокаменного пояса (Северная Карелия) // Литосфера. 2017. № 3. С. 102-126.

3. Левченков О.А., Милькевич Р.И., Миллер Ю.В., Зингер Т.Ф., Львов А.Б., МысковаТ.А., ШулешкоИ.К. $\mathrm{U}-\mathrm{Pb}$ возраст метаандезитов верхней части разреза супракрустальных образований северной части Тикшеозерского зеленокаменного пояса (Северная Карелия). 2003. Докл. АН. № 389(3). С. 378-381.

4. Милькевич Р.И., Миллер Ю.В., Глебовицкий В.А. и др. Толеитовый и известково-щелочной магматизм в северной части Тикшеозерского зеленокаменного пояса: геохимические признаки субдукционной обстановки // Геохимия. 2003. № 12. С. 1262-1274.

5. Милькевич Р.И., Мыскова Т.А., Глебовицкий В.А., Львов А.Б., Бережная Н.Г. Каликорвинская структура и ее положение в системе Северо-Карельских зеленокаменных поясов: Геохимические и геохронологические данные // Геохимия. 2007. № 5. С. 483-506.

6. Нефедов Е.В., Попова В.А., Сыромятина Н.Д. и др. О поисково-съемочных работах на редкие металлы, слюду и другие полезные ископаемые в южной части Кандалакшского района Мурманской области в 1958 году. ФГУ ТФИ по Мурм. обл. 1959.

7. Ремизова А.М. Отчет по составлению сводной легенды Кольской серии листов Государственной геологической карты Российской Федерации м-ба 1:200 000 (новая серия). ФГУ ТФИ по Мурм. обл. 1994. 